\title{
Reinventing The Future Online Education Using Emerging Technologies
}

\author{
Regina Reine ${ }^{1}$, Filbert H. Juwono ${ }^{2 *}$, W.K. Wong ${ }^{2}$ \\ ${ }^{1}$ Twigx Research, 71 - 75 Shelton Street, London WC2H 9JQ, United Kingdom; reginareine@twigxresearch.com \\ ${ }^{2}$ Department of Electrical and Computer Engineering, Curtin University Malaysia, Miri 98009, Sarawak, Malaysia \\ *Correspondence: filbert@ieee.org
}

SUBMITTED: 14 November 2021; REVISED: 23 November 2021; ACCEPTED: 24 November 2021

\begin{abstract}
The pandemic of Coronavirus Disease 2019 (COVID-19) has forced the teaching and learning activities to be conducted remotely. Before the pandemic, many academic institutions had offered online distance learning for selected courses. However, in practice, most of these programs were delivered as blended learning programs instead of fullfledged distance learning programs. Distance learning programs faced challenges and limitations in terms of communication, integrity, and interactions compared to the traditional face-to-face teaching and learning method. Despite the challenges and limitations in distance teaching and learning, academic staff is expected to accomplish the same (or better) outcomes than traditional face-to-face teaching and learning. Hence, the distance learning method was not popular with many academic staff and students before the pandemic time. In order to improve the quality of the full distance learning delivery, emerging technologies and more interactive platforms are being developed rapidly. This article discusses the emerging technologies and strategies to make full distance learning or remote education competitive compared to the traditional teaching and learning method. The future potential teaching and learning technology, i.e., digital twins, is also briefly presented.
\end{abstract}

KEYWORDS: Distance learning; digital twins; LMS; remote education; virtual laboratory; technology; COVID-19.

\section{Introduction}

The notion of distant learning has been around since the 1840s, when Sir Isaac Pitman began teaching shorthand to his acquaintances and siblings by mail [1-2]. Distance learning is principally distinguishable from conventional online learning (or e-learning) and there are at least three differences between them: remoteness and proximity, target clients, and cost [3]. In distance learning, teachers and students may be separated geographically and in time for distance learning [1]. Most communication and interactions are mostly via online platforms or email; teaching materials are delivered digitally (e.g. audio, video, or digital documents) either in a live session or a recorded session; assessments, quizzes, and examinations are conducted online; and remote laboratory activities. Due to the advancement of digital technologies and the new rules and regulations due to the COVID-19 epidemic, definitions and distinctions of (conventional) online learning and distance learning have become fuzzy. In this article, the 
terms "online learning," "distance learning," and "online distance learning" are used interchangeably and defined as remote teaching and learning activities using digital platforms. Distance learning, like traditional face-to-face learning, should be structured using the traditional course structure. Fig. 1 illustrates the design of online distance learning based on Problem-Based Learning (PBL). The learning outcomes of the course unit are determined by the course outcomes, which are translated into learning objectives. The syllabus is designed to accomplish the learning objectives.

In distance learning, the syllabus is specially designed and involves the development of online assignments, laboratory activities, and evaluation criteria. The challenges in a virtual or remote laboratory include how the students access laboratory equipment remotely to complete the tasks, how to evaluate the students' work remotely, how the students can collaborate as a team, and how to supervise the laboratory activities to maintain the integrity of the results.

For the examinations and assignments, materials can be created offline or online using the features in the Learning Management System (LMS) platform and made available for students at a specific time. The examination or assignment materials can be given offline or via the LMS platform to the students, where the answers should be uploaded on the LMS platform within a limited period to be evaluated by the academic staff. From the students' attainment, the course outcomes, unit outcomes, and learning objectives can be re-examined.

Students' feedback for teaching staff or course evaluation can also be requested via the LMS platform. The feedback is intended to continuously improve the teaching and learning performance in order to satisfy the course or unit outcomes. Based on the given feedback, action plans can be initiated to solve the existing problems or improve the quality of the teaching and learning experience.

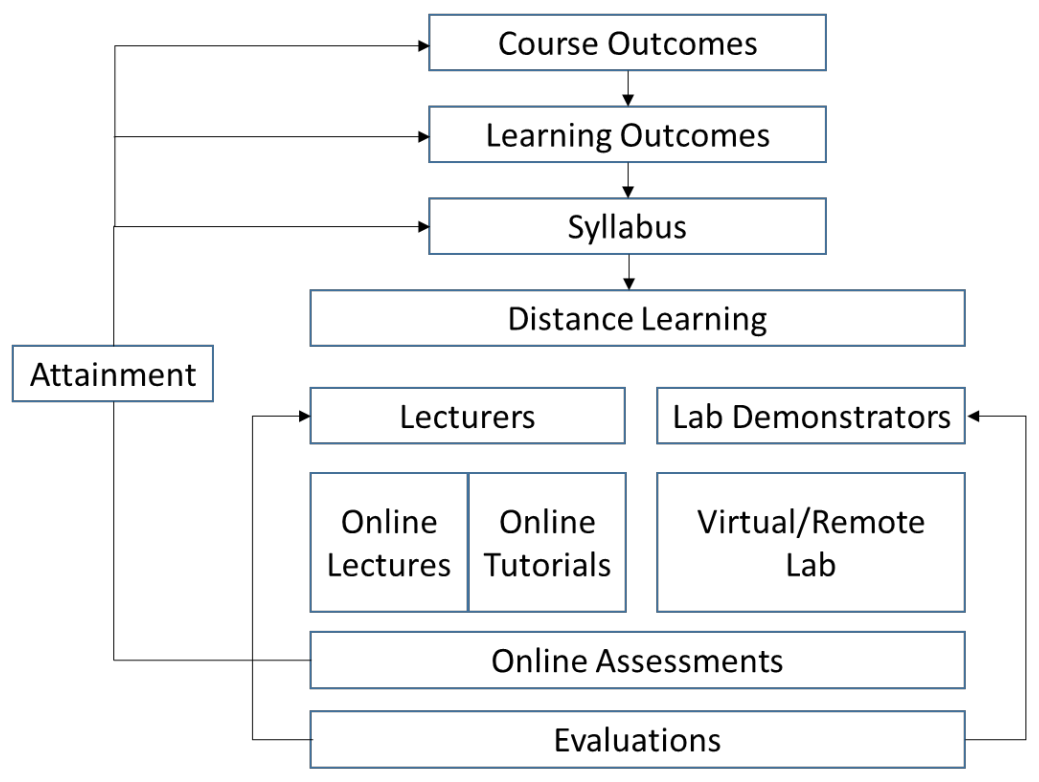

Figure 1. Design of online distance learning pedagogy.

In order to deliver high quality distance learning, supporting and enabling technologies and fully-trained academic staff play important roles in delivering high quality teaching and learning experiences. This article discusses several key emerging technologies for distance teaching and learning activities to fulfill the current standards in the curriculum. In addition, awareness of new potential technology, such as digital twins, is presented. 


\section{Implementing Distance Learning : Supporting Technologies}

\subsection{Learning Management System (LMS)}

The LMS platform provides various functionalities related to teaching and learning activities, such as online classrooms, virtual laboratories, and online assessments or examinations. In general, the LMS platform provides storage capabilities for storing teaching materials either on a dedicated physical server or on a cloud server for short or long term storage, communication functionalities (e.g. student forums, staff forums), different types of assignment submission (e.g. individual or group submission), online assessment feature, reporting/analytics tool, and an online classroom (live or recorded lecture classes) feature [45].

Live (real-time) lectures usually have a digital whiteboard, which is a necessity for some courses such as mathematics, science, and design courses. The live lecture sessions should have recording functionality to enable the students to record, save, and access the materials at any time. Recorded lectures should be available to all students for every live lecture session. This way, the students located in different time zones can receive the same teaching materials. Recorded lecture sessions are beneficial for examination preparation where the students can view the materials at their own pace. The recorded video and audio teaching method is also hugely beneficial for students who have learning difficulties such as dyslexia or Irlen syndrome as they do not necessarily have to read the text books as they can watch and listen the materials to study for their examination.

Some of the most well-known LMS platforms used by higher education institutions are Moodle (free open source), Blackboard (licensed), and Canvas (licensed). Depending on the pricing bracket, advanced features and functionalities are available in licensed LMS platforms. Moodle has been widely used by institutions globally due to its cost effectiveness, simple installation, Social Constructionist Pedagogy Method design-based, user-based framework, and it has more than 1600 plugins to enhance the online delivery experience [4-6]. Moodle provides different levels of user settings to differentiate between levels of access and authorities. System administrator (user is responsible for system operation, databases, and functionalities), teacher (user is only responsible for creating teaching materials, assignments, and other teaching activities), student (user can access selected course materials, submit assessment tasks, and other learning activities but does not have access to edit the teaching materials), and guest (user can access limited information or selected courses where log in is required).

Blackboard is a licensed platform where different level of subscriptions offers different features and functionalities [4-6]. Virtual classroom is available through the Blackboard Collaborate where the online lectures can be saved and recorded. Blackboard offers wide-range of functionalities in assessing tasks and exams such as dateline can be set automatically where late submissions will be rejected and allow multiple markers to evaluate an assignment (to give fairness in evaluation, the mark can be hidden from the other markers). In order to maintain the integrity of the students' works, plagiarism functionality will easily compare the similarity of one's work to others' in a short period of time. 


\subsection{Remote and Virtual Laboratories}

In distance learning, laboratory activities can be conducted via remote laboratory (students are connected to real experiment equipment through the Internet) or virtual laboratory (simulation is used to represent the real laboratory experiment). The concepts of remote and virtual laboratories are illustrated in Fig. 2a and 2b, respectively.

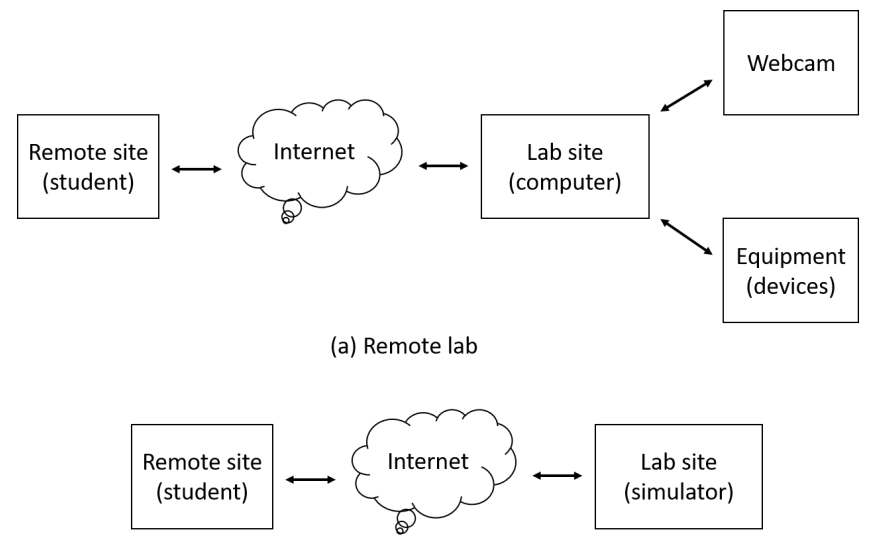

(b) Virtual lab

Figure 2. Concepts of remote laboratory and virtual laboratory. The equipment in a remote laboratory is accessed over the Internet and viewed via a camera. In a virtual laboratory, a model of a system is created as a simulation that can be viewed on one's own device or on another computer/server via an Internet connection.

Both remote and virtual laboratories offer flexibility in terms of time and place compared to the traditional academic laboratory [7]. As the remote laboratory uses real equipment and data, students can gain more knowledge as if they were physically in the laboratory. The initial setup for a remote laboratory can be simple. Simple experiments may only require webcams, computers, and remote access to use the equipment in the "real" laboratory. Hence, setting up a remote laboratory is relatively low-cost and fast. On the other hand, a virtual laboratory can be more interactive for the students as it is made in the form of a simulation program. However, the results are based on ideal data, which may not be true in practice.

One of the challenges in using either remote laboratory or virtual laboratory is the difficulty in monitoring student engagement, as online discussion may not be as effective as discussion in person. Some students may find it difficult to contribute to online discussion. Another issue is that some may view remote laboratory experience as a "lack" of practical experience.

To observe the performance of a remote laboratory, the authors set up a remote laboratory for the Microcomputers unit in Semester 2, 2020, at Curtin University Malaysia [8]. The remote laboratory setup is illustrated in Fig. 3. A task was created for the students to create programs to control the LEDs on an MSP430 board based on a given pattern. A virtual private network (VPN) was used and the students connected to the MSP430 board remotely. Students can view the results of their programs via the camera attached to the physical laboratory. This creates a virtual environment as if they are in a laboratory at Curtin University Malaysia. 


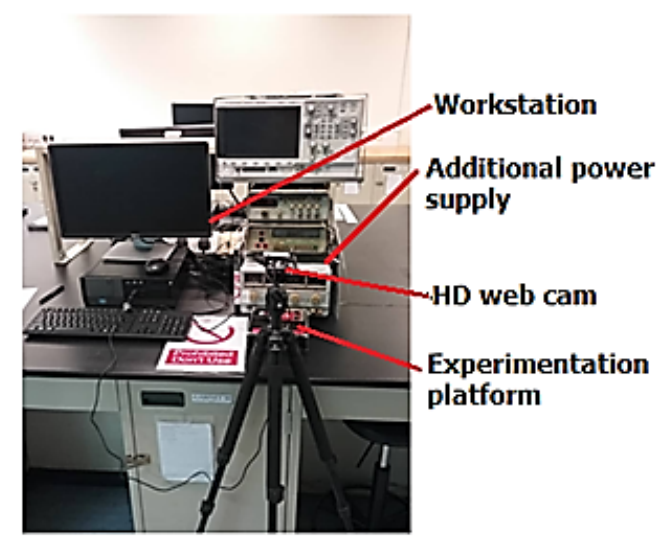

Figure 3. Remote laboratory setup for Microcomputers unit.

Another example that the authors observe in Curtin University Malaysia is the use of a virtual laboratory for the control system unit. Fig. 4 illustrates a virtual laboratory for control system units to simulate a closed-loop transfer function. Matlab Simulink is used to observe the dynamics of the system and to analyse different performance and feedback related to various gains and different transfer functions.
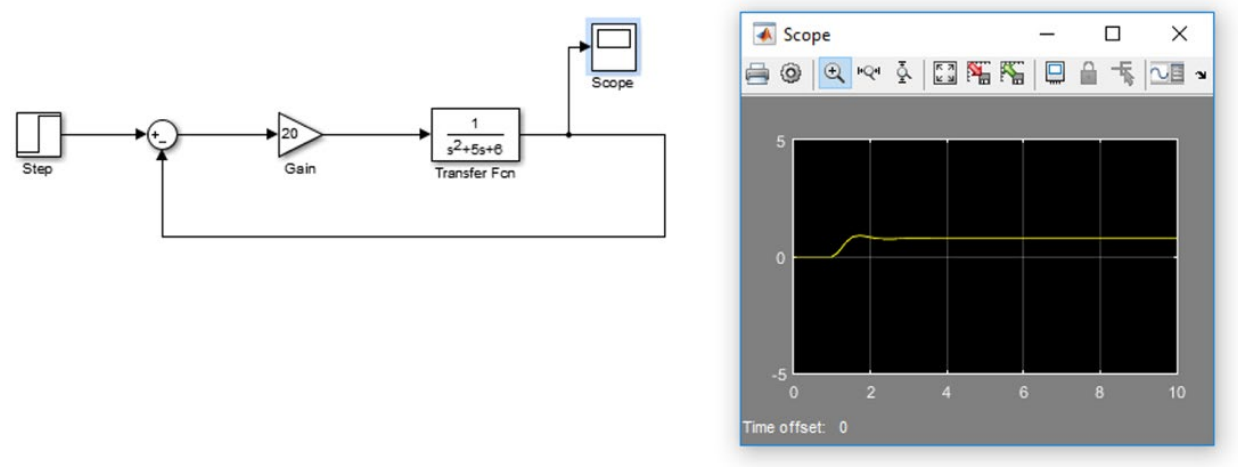

Figure 4. Virtual laboratory for Control System unit.

Currently, more complex experiments (e.g. chemical experiments) are hard to conduct virtually or remotely. In the future, a remote laboratory can accommodate complex experiments when suitable technologies with smart automation have been developed.

\subsection{Interactive Quizzes}

Interactive quizzes can be an alternative type of assessment for some courses [9-10]. Quizzes can be made using LMS, but this may not be in an interactive environment. A gamification assessment approach can be used for a more interactive engagement. Kahoot! and Socrative platforms are well-known for gamification quizzes. A quiz can be used in the live lecture or tutorial session to understand the student's comprehension of a particular topic; remote students can also participate in real time.

With the assumption that most students have mobile phones, this activity is efficient and effective as it can be conducted in a very short time with simple or little preparation. Music, pictures, or videos can be easily embedded to make the learning experience more enjoyable. The gamification method is popular as it shows a significant reduction in the stress level of the 
students. However, using gamification quizzes is not sufficient to evaluate the students' ability, and the problem persists with students in different time zones who are not able to attend live lectures or tutorial sessions.

\subsection{Remote Invigilation}

One important issue in distance learning examination is to evaluate and to justify the integrity of the students' works. If the exam problems set in the LMS platform, the students can download and solve it for a certain duration before uploading the answers to the platform. The major challenge is to find the efficient and effective ways to monitor and supervise the students during the exam period to ensure that the students do not cheat and that the exam is not conducted by another person.

A remote invigilation technology called the Intelligent Remote Invigilation System (IRIS Invigilation) has been developed to tackle this issue. IRIS will record video of the student's face during the exam duration, and it uses artificial intelligence to detect any unusual movement of the eyes and head. IRIS will verify the student before the exam, and the webcam must be turned on during the exam period. It is effective for the examination of a small group of students, but it is still not sufficient for major examination conditions.

\section{Enabling Technologies for Distance Learning}

\subsection{G/6G Communication Systems}

Distance learning necessitates fast and dependable Internet connections, which are critical to its success.5G wireless communication supports data rates of up to $10 \mathrm{Gbps}$ uplink and 20 Gbps downlink [11], while 6G wireless communication is expected to support data rates of up to $1 \mathrm{Tbps}$ [12].With 5G/6G wireless communication, high capacity can be achieved where a large number of students accessing the course materials from different locations can be satisfied, multiple live lecture sessions at one time can be delivered, continuous video streaming 24/7 can be easily available, and new emerging technologies such as immersive virtual reality can be used to enhance the distance learning experience.

5G/6G wireless communication supports human-machine communication and machine-to-machine (M2M) communication. M2M communication will be useful for remote laboratory implementation where the remote equipment can communicate easily with the students' computers or mobile devices.

\subsection{Big Data and Data Analytics}

The International Data Corporation (IDC) predicted that the volume of data could reach up to 175 zettabytes by 2025 due to the massive deployment of sensors, the increasing use of $5 \mathrm{G} / 6 \mathrm{G}$ wireless networks, and the use of heavy-data applications, block chain, and edge computing.

With distance learning and online platforms, academic institutions can easily collect data over a short or long period of time for different objectives. For example, data can be collected from the students to improve their performance and to improve the teaching and learning activities. Data analytics can be performed using smart algorithms to identify and solve repeat problems that have occurred in distance learning [13]. 


\subsection{Artificial Intelligence}

Artificial intelligence (AI) refers to a set of algorithms that enable machines to learn and adapt like a human does. In order to make a decision, AI highly depends on training data. To make a decision, training data are created with specific knowledge and parameters. The training data can be updated from time to time to improve the performance of artificial decisions or solutions.

From the application perspective, AI can simply be divided into two types: supervised algorithms and unsupervised algorithms. In supervised algorithms, the learning process includes labeled data, and in unsupervised algorithms, the algorithms extract patterns from the data provided.

Two scenario examples of using AI in the education sector are: 1) analyzing the learning patterns of the students [14] and 2) evaluating and monitoring online assignments or examinations [15]. In the first scenario, data can be extracted from sensors (e.g., cameras) or from digital footprints from the login and can be used to analyze patterns of students' academic behavior (e.g., frequency of students' login, frequency and duration of the students accessing various materials, or the range of time of assignment submission). Based on the data, a correlation between the students' behavior and performance can be created. This may lead to an early identification of a problem or finding the solution to improve the students' or academic staff's performance. In the second scenario, AI can be embedded in the software to detect plagiarism patterns during online assessment.

\subsection{Sensors and Internet of Things (IoT)}

Data is the key component to build smart distance learning platforms. Sensors or Internet of Things (IoT) such as camera, motion, audio, and image sensors are used to get information from the environment [16].

In the IRIS invigilation system, the camera sensor serves as the physical sensor. Another example is the wearable sensor, which may be used to track a student's actions in order to build a more customized learning style.

\subsection{Augmented Reality (AR) and Virtual Reality (VR)}

Emerging technologies such as immersive technologies (e.g., AR and VR) can enhance the experience of teaching and learning in distance learning [17]. To create an immersive environment in virtual reality, AR or VR headsets are required.

When the virtual environment is created, the students and the lecturers will have the sensation of the "classroom feeling," where they think that they are in the same room or location. This "classroom feeling" may increase the concentration and motivation of the students. The VR environment provides significant benefits for teamwork and project collaboration, especially for design assignments or engineering courses. The downside is that everyone must have the headsets to create the virtual environment. The university may not have the budget to supply the headsets for all of the academic staff and students.

In AR, 2D objects are augmented and converted into 3D objects. Medical students will be able to observe and study body anatomy without having to use the real body. Engineering 
students can design a prototype without wasting real materials. Architecture and civil engineering students can design a prototype of the house in AR where it can provide a better visual and be more interactive compared to conventional 2D drawing.

Users can review the learning materials as many times as they need to use VR and AR technology. As a result, it creates time and space flexibility. An example of the usage of VR in education is the Stanford LEAD Certificate Program, which has utilized VR technology to allow students to gather in a virtual classroom and engage with one another [18]. Another example is VR Chat [19], which was utilized in a lecture at the University of British Columbia in Canada with students wearing Oculus Rift headsets.

\section{The Potential of Digital Twins}

A digital twin is a part of Industry 4.0 in which the virtual copy of a real-world system is brought to the digital world. The concept originated from the Apollo program of NASA, where two identical spacecraft were designed. One spacecraft was launched into orbit, while the other remained on Earth. When a problem arose in space, the engineers could replicate the problem on Earth, model the solution on the replica, and transmit the solution to the crew in space.

In education, digital twins combined with cognitive skills will create a cognitive digital twin [20]. The concept of a cognitive digital twin is illustrated in Fig. 5, where the concept is more than just a model or simulation. The key distinctions of digital twins compared to remote or virtual laboratories are that digital twins use sensors or actuators to collect large amounts of data. The data collected from the LMS platform or from sensors is used as an input (e.g. examination results, popular courses, peak time of login, duration of login at various times, courses with poor attendance, etc.). The collected data is processed with the help of AI for decision making, trend analysis, and performance analysis. Through actuators, the decisions may be transmitted back to the physical system to implement action plans.

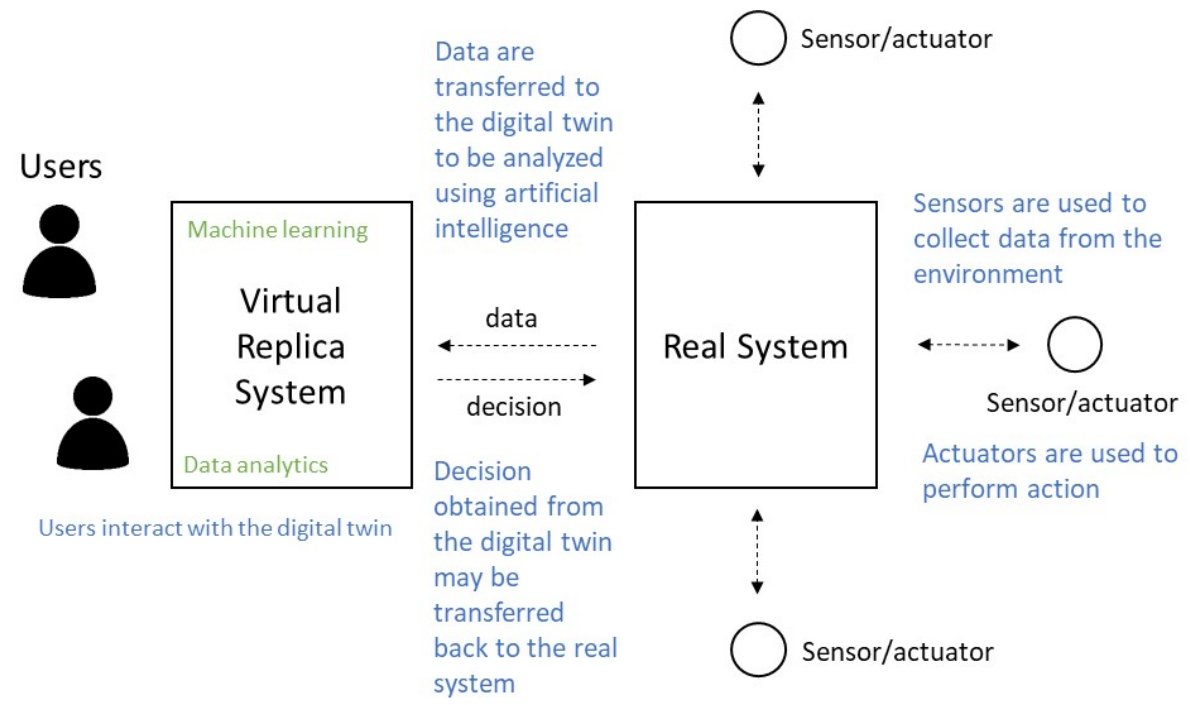

Fig 5. Concept of a digital twin.

The concept of a cognitive digital twin will be a game changer for laboratory and fieldwork internships. The key distinctions between digital twins and remote or virtual laboratories are 
that digital twins use sensors or actuators to collect large amounts of data, are able to transmit high rates of data anytime to anyone, anywhere, and have the functionality to make new decisions to improve the system using AI.

With the help of AI and VR, students in the field work program are not required to visit the actual location to learn about the real system; they can be either at home or at a particular location. Fieldwork experience will no longer be restricted by time and distance. In the future, a digital twin of the classroom can be constructed where students no longer attend the real class site as everything is a copy of the real class environment.

A digital twin may be utilized for a variety of purposes, including business, research, and community service. The digital twin concept can be used by city planners (or students) to design, for example, a PV panel system that requires the greatest amount of solar energy. Virtual Singapore [21], a 3-D representation of Singapore, is an example of the implementation of a digital twin, which can be potentially used for educational purposes as well. In particular, Virtual Singapore offers the following capabilities:

- Virtual experiments.

It can be used to assess the coverage of $3 \mathrm{G} / 4 \mathrm{G}$ communication networks and indicate places with weak communication signals.

- Virtual test-bedding.

It can be used to test new services, such as a new sports hub with semantic information.

- Planning and decision-making.

It provides a comprehensive and integrated platform for developing analytical applications that can be used for planning and decision-making.

- Research and development.

The data collected by sensors can be used for further research and development.

\section{Conclusion}

The COVID-19 pandemic is considered a watershed moment for the future education sector. This article discussed the potential of distance learning to be the future of teaching and learning experiences. Several educational technologies supporting online learning have been presented. In addition, enablers for future educational technologies have been discussed. Finally, while the experience of online distance learning may not be identical to that of traditional face-toface learning, with the support of the latest emerging technologies and continuous improvement, similar or better outcomes can be achieved.

\section{Competing Interest}

The authors declare no financial or non-financial competing interests.

\section{References}

[1] Buselic, M. (2012). Distance learning - concepts and contributions. Oeconomica Jadertina, 2, 23 34., http://dx.doi.org/10.15291/oec.209.

[2] Archibald D.; Worsley, S. (2019). The father of distance learning. TechTrends, 63, 100-101. http://dx.doi.org/10.1007/s11528-019-00373-7.

[3] Guri-Rosenblit, S. (2005). Distance education' and 'e-learning': Not the same thing. Higher Education, 49, 467-493, 2005. http://dx.doi.org/10.1007/s10734-004-0040-0. 
[4] Subramanian, P.; Zainuddin, N.; Alatawi, S. (2014). A study of comparison between Moodle and Blackboard based on case studies for better LMS. Journal of Information Systems Research and Innovation, 6, 26-32.

[5] Cavus, N. (2015). Distance learning and learning management systems. Procedia - Social and Behavioral Sciences, 191, 872-877. https://doi.org/10.1016/j.sbspro.2015.04.611.

[6] Momani, A.M. (2010). Comparison between Two Learning Management Systems: Moodle and Blackboard. SSRN Electronic Journal, 2, 54. http://dx.doi.org/10.2139/ssrn.1608311.

[7] Nedic, Z.; Machotka, J.; Nafalski, A. (2003). Remote laboratories versus virtual and real laboratories. Frontiers in Education, 1, T3E1. http://dx.doi.org/10.1109/FIE.2003.1263343.

[8] Wong, W.K.; Juwono, F.H.; Loh, W.N. (2020). Remote implementation of microcomputers laboratory practices: A case study. The Sixth International Conference on e-Learning (ECONF20), 214-218. https://doi.org/10.1109/econf51404.2020.9385488.

[9] Prieto, M.C.; Palma, L.O.; Tobias, P.J.B., leon, F.J.M. (2019). Student assessment of the use of Kahoot in the learning process of science and mathematics. Education Sciences, 9, 1-13. https://doi.org/10.3390/educsci9010055.

[10] Bicen H.; Koyakocun, S. (2018). Perceptions of students for gamification approach: Kahoot as a case study. International Journal of Emerging Technologies in Learning, 13, 72-93. http://dx.doi.org/10.3991/ijet.v13i02.7467.

[11] Shafi, M.; Molisch, A.F.; Smith, P.J.; Haustein, T.; Zhu, P.; De Silva, P.; Tufvesson, F.; Benjebbour, A.; Wunder, G. (2017). 5G: A Tutorial Overview of Standards, Trials, Challenges, Deployment, and Practice, IEEE Journal on Selected Areas in Communications, 35, 1201-1221. https://doi.org/10.1109/JSAC.2017.2692307.

[12] Jiang, W.; Han, B.; Habibi M.A.; Schotten, H.D. (2021). The Road Towards 6G: A Comprehensive Survey. IEEE Open Journal of the Communications Society, 2, 334-366, https://doi.org/10.1109/OJCOMS.2021.3057679.

[13] Crespo R.G.; Burgos, D. (2019). Advanced Sensors Technology in Education. Sensors, 19, 4155. https://doi.org/10.3390/s19194155.

[14] Yan, N.; Au, O.T.S. (2019). Online learning behavior analysis based on machine learning. Asian Association of Open Universities Journal, 14, 97-106. https://doi.org/10.1108/AAOUJ-08-20190029 .

[15] Deo, R.C.; Yaseen, Z.M.; Al-Ansari, N.; Nguyen-Huy, T.; Langlands T.A.M.; Galligan, L. (2020). Modern Artificial Intelligence Model Development for Undergraduate Student Performance Prediction: An Investigation on Engineering Mathematics Courses. IEEE Access, 8, 136697136724. https://doi.org/10.1109/ACCESS.2020.3010938.

[16] Liu, M.C.; Lai, C.H.; Su, Y.N.; Huang, S.H.; Chien, Y.C.; Huang, Y.M.; Hwang, J.P. (2015) Learning with Great Care: The Adoption of the Multi-sensor Technology in Education. In Sensing Technology: Current Status and Future Trends III. Smart Sensors, Measurement and Instrumentation, vol 11; Mason, A., Mukhopadhyay, S., Jayasundera, K., Eds. Springer, Cham. https://doi.org/10.1007/978-3-319-10948-0 11.

[17] Lee, J.H.; Shvetsova, O.A. (2019). The impact of VR application on student's competency development: A comparative study of regular and VR engineering classes with similar competency scopes. Sustainability, 11, 8. https://doi.org/10.3390/su11082221.

[18] From Virtual to Reality, Online LEAD Program Exceeded Expectations. Accessed: 12 June 2021) Available Online: https://www.gsb.stanford.edu/experience/news-history/virtual-reality-onlinelead-program-exceeded-expectations.

[19] 'VR Chat' Used to Deliver One of the First University Lectures in Virtual Reality. Accessed: 12 June 2021. Available Online: https://www.roadtovr.com/vr-chat-helps-deliver-first-virtualuniversity-lecture/. 
[20] Madni, A.M.; Erwin, D.; Madni, A. (2019). Exploiting digital twin technology to teach engineering fundamentals and afford real-world learning opportunities. 2019 ASEE 126th Annual Conference and Exposition. http://dx.doi.org/10.18260/1-2--32800.

[21] Virtual Singapore Accessed: 12 June 2021. Available Online: https://www.nrf.gov.sg/programmes/virtual-singapore.

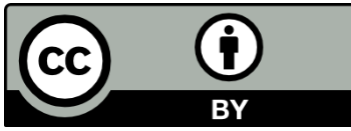

(C) 2021 by the authors. This article is an open access article distributed under the terms and conditions of the Creative Commons Attribution (CC BY) license (http://creativecommons.org/licenses/by/4.0/). 